\title{
NATURAL RESOURCES FROM PLANTS IN THE TREATMENT OF CANCER: AN UPDATE
}

\author{
PARUL TRIPATHI, ADITI SINGH*
}

Amity Institute of Biotechnology, Amity University, Lucknow Campus, Malhaur, Gomti Nagar Extension, Lucknow - 226 028, Uttar Pradesh, India. Email: Asingh3@lko.amity.edu

Received: 31 January 2017, Revised and Accepted: 04 March 2017

ABSTRACT

Cancer has become the second leading cause of death worldwide. The incidences of cancer are rising at an alarming rate but it can be reduced and controlled by evidence-based strategies for cancer prevention, early detection, and management of patients with cancer. Historically, it is proven that plants and their metabolites have great potential in the treatment of various acute diseases as well as chronic disorders. The novel bioactive compounds from many plants are being studied as potential therapeutic agents because of their high activity and low toxicity. This review gives a comprehensive description of such medicinal plants which have been studied as potentially effective against cancer.

Keywords: Ethnopharmacology, Cancer treatment, Drugs, Plants, Antitumor activity, Medicinal plants.

(C) 2017 The Authors. Published by Innovare Academic Sciences Pvt Ltd. This is an open access article under the CC BY license (http://creativecommons. org/licenses/by/4. 0/) DOI: http://dx.doi.org/10.22159/ajpcr.2017.v10i7.17399

\section{INTRODUCTION}

Cancer is an abnormal malignant growth of body tissue or cell which can occur on any part of the body. According to the World Health Organization (WHO), cancer is among leading cause of morbidity and mortality worldwide with approximately 14 million new cases and more than 8 million cancer-related deaths in 2012, and an expected rise of new cases by $70 \%$ within two decades [1]. A correct cancer diagnosis is essential for adequate and effective treatment because every cancer type requires a specific treatment regimen [2]. And thus, cancer treatment and prevention becomes a major focus area for scientists worldwide. The most common types of the treatment for cancers include surgery, chemotherapy, radiotherapy, and targeted therapy. Most cancer patients have to undergo some form of surgery whether to diagnose, treat or prevent cancer and it has been found to be of great help if cancer has not spread to other parts of body. The use of medicines or drugs as cancer treatment is chemotherapy. There are more than 100 chemotherapy drugs for cancer in use these days which vary in composition and mode of action. Radiotherapy is when high energy particles destroy cancer cells. It is the most common treatment for cancer. A more recent method is targeted therapy where substances attack specific cancer cells, minimizing damage to normal cells. The priority now is to have new therapeutic alternatives. One such approach is iron depletion strategy based on metal chelation in tumoral environment [3].

The use of herbs as medicines is believed to have its presence from the ancient times [4]. The first record on the medicinal use of plants was written in about 2600 BC from the Akkaidians and Sumerians [5]. Egyptian medicinal text, "Ebers Papyrus" from 1500 BC had consisted of over 700 drugs. Around 1100 BC, the Chinese Materia Medica came with the data of approximately 600 medicinal plants [6]. Medical methodologies of treatment as mentioned in Ayurveda are recorded in Susruta and Charaka dating from about 1000 BC [7]. The Greeks also contributed substantially to the rational development of herbal drugs. In 1950s, modern medicine began more systematically examining natural agents as a source of useful anticancer substances [8].

It has always been argued that "the use of natural products has been the single most successful strategy in the discovery of novel drugs" [9]. Traditional medical science is completely dedicated toward plants or animal based products in treatment or prevention of disease as well as the well-being of people. Commonly used plants in the treatment of various diseases are Zingiber officinale, Camellia sinensis, Curcuma longa, Aloe vera, etc. [10]. Molecules derived from natural sources such as plants, marine organisms, and microorganisms have played and are still playing a dominant role in the discovery of leads for the development of drugs for most human diseases.

According to the WHO (2008), about three quarters of the world's population currently uses herbs or other forms of traditional medicines to treat illness. Even in the USA, the use of plants and phytomedicines has increased dramatically [11]. It has been also reported [12] that more than $50 \%$ of all modern drugs in clinical use are of natural origin; many of them have the ability to induce apoptosis in various cancer cells of human origin. Worldwide, scientists are continuously studying the vast variety of plants for their anticancerous activity against different types of malignancies but it is equally important that their findings are available for others to take lead. Therefore, an effort has been made here to compile all such studies in which plants having anticancer activities are documented.

The methodology for this review article has been an exhaustive literature survey of published work in research journals available in PubMed, Medline, Science Direct, and other such online libraries. The effort is to include all possible published work without going for time frame. The search was done with following keywords - drug therapy, alternative therapy for cancer, ethnopharmacology, plants in cancer treatment, natural sources for cancer treatment, complementary medicine, etc. All review, research articles and case reports were studied and included. A total of 1034 articles were identified, of which 496 were excluded at initial screening. Remaining papers were studied, and around 253 most relevant papers and studies are included, indexed, and described in this review Table 1 elaborates on all such studied plants along with their common name, family, anticancer activity and other medicinal properties.

\section{DISCUSSION}

Cancer, like any other fatal disease, is a cause of concern to the medical community worldwide. It causes serious implications on the patient, and there are generally severe side effects also of the treatment which the patient suffers consequently. The use of natural substances obtained from the plants is the need of the hour. They may have potential to prevent and cure cancer with least side effects.

There are a number of plants which have given promising results against a particular condition. For example, several workers have seen 
Table 1: Studies on plants for their anticancer and other medicinal properties

\begin{tabular}{|c|c|c|c|c|}
\hline Plant name & Family & Native place & Anticancer activity & Other medicinal properties \\
\hline $\begin{array}{l}\text { Aegle marmelos (L.) } \\
\text { Corrêa (bael) }\end{array}$ & Rutaceae & India & $\begin{array}{l}\text { Activity against lymphomas, breast } \\
\text { cancer [13], ascites melanomas, } \\
\text { and leukemia [14] induction of } \\
\text { apoptosis [15] }\end{array}$ & \\
\hline Allium sativum L. (garlic) & Amaryllidaceae & Central Asia & $\begin{array}{l}\text { Used against breast cancer, prostate } \\
\text { cancer [16], leukemia[17] intestinal } \\
\text { cancer [18], stomach cancer [19] }\end{array}$ & \\
\hline Aloe barbadensis (aloe) & Xanthorrhoeaceae & $\begin{array}{l}\text { Yemen, Sudan and } \\
\text { Somalia }\end{array}$ & $\begin{array}{l}\text { Inhibits growth and spread of } \\
\text { liver cancer, stomach cancer } \\
\text { and various sarcomas [20], } \\
\text { chemoprevention [21] }\end{array}$ & Wound healing activity [22] \\
\hline $\begin{array}{l}\text { Alpinia galangal (Thai } \\
\text { galangal) }\end{array}$ & Zingiberaceae & $\begin{array}{l}\text { South Asia and } \\
\text { Indonesia }\end{array}$ & $\begin{array}{l}\text { Activity against lung cancer, breast } \\
\text { cancer, stomach cancer, prostate } \\
\text { cancer [23], colon cancer, leukemia } \\
\text { and multiple myeloma }[24,25]\end{array}$ & \\
\hline $\begin{array}{l}\text { Amoora rohituka (pithraj } \\
\text { tree) }\end{array}$ & Meliaceae & Asia (U.P. East) & $\begin{array}{l}\text { Inhibits growth of pancreatic, } \\
\text { breast and cervical cancers [26] }\end{array}$ & \\
\hline $\begin{array}{l}\text { Amorphophallus } \\
\text { konjac (elephant yam) }\end{array}$ & Araceae & $\begin{array}{l}\text { Subtropical to } \\
\text { Tropical Eastern } \\
\text { Asia }\end{array}$ & Activity against lung cancer [27] & \\
\hline $\begin{array}{l}\text { Andrographis } \\
\text { paniculata (Maha tita) }\end{array}$ & Acanthaceae & $\begin{array}{l}\text { Southern and } \\
\text { Southeastern Asia }\end{array}$ & $\begin{array}{l}\text { Activity against cancers of breast, } \\
\text { kidney, colon, prostate, ovary, } \\
\text { stomach, nasopharynx malignant } \\
\text { melanoma and leukemia [28-30] }\end{array}$ & $\begin{array}{l}\text { Atherosclerosis, and } \\
\text { diabetes }[31,32]\end{array}$ \\
\hline Annona triloba (pawpaw) & Annonaceae & $\begin{array}{l}\text { United States, } \\
\text { South to Northern } \\
\text { Florida and Eastern } \\
\text { Texas }\end{array}$ & $\begin{array}{l}\text { Active against certain breast and } \\
\text { lung cancers }[33]\end{array}$ & \\
\hline $\begin{array}{l}\text { Arachis } \\
\text { hypogaea (groundnut) }\end{array}$ & Fabaceae & South America & $\begin{array}{l}\text { Have general anticancer } \\
\text { activity [34] }\end{array}$ & $\begin{array}{l}\text { Prevent cardiovascular } \\
\text { conditions, aid in weight loss } \\
\text { lower cholesterol, antioxidant } \\
\text { activity [35] }\end{array}$ \\
\hline $\begin{array}{l}\text { Aronia } \\
\text { melanocarpa (chokeberrie) }\end{array}$ & Rosaceae & $\begin{array}{l}\text { Eastern North } \\
\text { America }\end{array}$ & $\begin{array}{l}\text { Activity studied against Colorectal } \\
\text { cancer [36], colon cancer [37] }\end{array}$ & Cardiovascular disease [38] \\
\hline $\begin{array}{l}\text { Artemisia annua (sweet } \\
\text { wormwood) }\end{array}$ & Asteraceae & Temperate Asia & $\begin{array}{l}\text { Studied for Leukemia } \\
\text { treatment [39] }\end{array}$ & \\
\hline $\begin{array}{l}\text { Asparagus officinalis (garden } \\
\text { asparagus) }\end{array}$ & Asparagaceae & $\begin{array}{l}\text { Europe, Northern } \\
\text { Africa and Western } \\
\text { Asia }\end{array}$ & $\begin{array}{l}\text { Potential inhibitory activity of } \\
\text { saponins on tumor growth and } \\
\text { metastasis [40] }\end{array}$ & \\
\hline $\begin{array}{l}\text { Asparagus } \\
\text { racemosus (shatavari) }\end{array}$ & Asparagaceae & $\begin{array}{l}\text { Sri Lanka, India } \\
\text { and the Himalayas }\end{array}$ & $\begin{array}{l}\text { Activity against human } \\
\text { breast cancer, human colon } \\
\text { adenocarcinoma human kidney } \\
\text { carcinoma, tumors[41] renal cell } \\
\text { carcinoma [42] }\end{array}$ & $\begin{array}{l}\text { Dyspepsia, hypertension, } \\
\text { nervous disorders, } \\
\text { tuberculosis, bronchitis, } \\
\text { cough, gonorrhea, } \\
\text { hyperacidity, leucorrhea, } \\
\text { epilepsy, leprosy, fatigue, colic } \\
\text { hemorrhoids, cardiac }[43,44]\end{array}$ \\
\hline $\begin{array}{l}\text { Astragalus } \\
\text { gummifera (milkvetch) }\end{array}$ & Fabaceae & $\begin{array}{l}\text { Temperate regions } \\
\text { of the Northern } \\
\text { Hemisphere }\end{array}$ & $\begin{array}{l}\text { Prevents cancer before it } \\
\text { begins [45] }\end{array}$ & \\
\hline Azadirachta indica (neem) & Meliaceae & India & $\begin{array}{l}\text { Activity against cancers of breast, } \\
\text { lung, stomach, prostate and } \\
\text { skin }[46,47] \text {, Antitumor activity }[48]\end{array}$ & \\
\hline Bacopa monnieri (brahmi) & Plantaginaceae & $\begin{array}{l}\text { Southern India, } \\
\text { Australia, Europe, } \\
\text { Africa, Asia, and } \\
\text { America }\end{array}$ & $\begin{array}{l}\text { Anticancer activity [49], Ascites } \\
\text { Carcinoma [50] }\end{array}$ & $\begin{array}{l}\text { Anti-inflammatory [51], } \\
\text { digestive, cardiotonic, } \\
\text { anticonvulsant [52], } \\
\text { depurative, sudorfic, } \\
\text { bronchodialator, diuretic [53] }\end{array}$ \\
\hline $\begin{array}{l}\text { Berberis vulgaris (European } \\
\text { barberry) }\end{array}$ & Berberidaceae & $\begin{array}{l}\text { Europe, Africa and } \\
\text { Asia }\end{array}$ & $\begin{array}{l}\text { Anticancer activity against } \\
\text { prostate cancer, liver cancer and } \\
\text { leukemia [54] antitumor [55-57] }\end{array}$ & $\begin{array}{l}\text { Antidiarrheal, antiarrhythmic } \\
\text { anti-inflammatory, } \\
\text { fever reducing, } \\
\text { analgesic (pain-reducing) } \\
\text { effects }[58,59]\end{array}$ \\
\hline $\begin{array}{l}\text { Bleekeria } \\
\text { vitiensis (markgraf) }\end{array}$ & Apocynaceae & $\begin{array}{l}\text { Tropics and } \\
\text { Subtropics }\end{array}$ & Treatment of breast cancer [8] & \\
\hline $\begin{array}{l}\text { Brassica oleracea (wild } \\
\text { cabbage) }\end{array}$ & Brassicaceae & $\begin{array}{ll}\text { Coastal } & \text { Southern } \\
\text { and } & \text { Western } \\
\text { Europe } & \end{array}$ & $\begin{array}{l}\text { Reduces the risk of some cancers } \\
\text { such as colorectal, breast [60], liver, } \\
\text { lung, prostate, skin, stomach, and } \\
\text { bladder cancers [61] }\end{array}$ & \\
\hline
\end{tabular}


Table 1: (Continued...)

\begin{tabular}{|c|c|c|c|c|}
\hline Plant name & Family & Native place & Anticancer activity & Other medicinal properties \\
\hline $\begin{array}{l}\text { Bupleurum scorzonera } \\
\text { folium (Chai Hu) }\end{array}$ & Apiaceae & East Asia & Studied for Osteosarcoma [62] & \\
\hline Camellia sinensis L. (tea tree) & Theaceae & $\begin{array}{l}\text { East, South and } \\
\text { South East Asia }\end{array}$ & $\begin{array}{l}\text { Prevents colon, prostate and } \\
\text { gastric cancers }[63,64] \text {, blood } \\
\text { vessel growth in tumors, skin } \\
\text { cancer }[22,65]\end{array}$ & \\
\hline $\begin{array}{l}\text { Camptotheca } \\
\text { acuminata (happy tree, } \\
\text { cancer tree) }\end{array}$ & Nyssaceae & $\begin{array}{l}\text { Southern China } \\
\text { and Tibet }\end{array}$ & $\begin{array}{l}\text { Used as drugs for cancer } \\
\text { treatment [66] }\end{array}$ & \\
\hline $\begin{array}{l}\text { Carmona retusa (Fukien tea } \\
\text { tree) }\end{array}$ & Boraginaceae & $\begin{array}{l}\text { Eastern and } \\
\text { South-Eastern Asia }\end{array}$ & $\begin{array}{l}\text { Anticancer activity on HepG2 cell } \\
\text { lines and significant activation of } \\
\text { caspase-3 [67] }\end{array}$ & \\
\hline $\begin{array}{l}\text { Catharanthus } \\
\text { roseus (Madagascar } \\
\text { periwinkle) }\end{array}$ & Apocynaceae & India and Sri Lanka & $\begin{array}{l}\text { Treatment of cancers such as } \\
\text { leukemias, breast and lung } \\
\text { cancers, lymphomas, Kaposi's } \\
\text { sarcoma and advanced testicular } \\
\text { cancer }[8,68,69]\end{array}$ & $\begin{array}{l}\text { Antidiabetic, antiulcer, } \\
\text { antibacterial, antioxidant, } \\
\text { antidiarrheal, antihelminthic, } \\
\text { hypotensive property }[70,71]\end{array}$ \\
\hline $\begin{array}{l}\text { Codonopsis pilosula (poor } \\
\text { man's ginseng) }\end{array}$ & Campanulaceae & China and Korea & $\begin{array}{l}\text { Immunological and hematopoietic } \\
\text { effect for the patients } \\
\text { undergoing chemotherapy or } \\
\text { radiotherapy [72-74] }\end{array}$ & \\
\hline Coleus forskohlii (coleus) & Lamiaceae & South America & $\begin{array}{l}\text { Forskolin a diterpene produced } \\
\text { by the roots, raises intracellular } \\
\text { cAMP levels and thus may act as an } \\
\text { effective anticancer agent [75] }\end{array}$ & \\
\hline $\begin{array}{l}\text { Combretum } \\
\text { caffrum (bushwillow tree) }\end{array}$ & Combretaceae & South Africa & $\begin{array}{l}\text { Active against lung, colon and } \\
\text { leukemia cancers [76] }\end{array}$ & \\
\hline $\begin{array}{l}\text { Crocus sativus (saffron } \\
\text { crocus) }\end{array}$ & Iridaceae & Italy and Iran & Having anticancer properties [77] & \\
\hline Curcuma longa (turmeric) & Zingiberaceae & South Asia & $\begin{array}{l}\text { Studied in colorectal cancer, } \\
\text { gastrointestinal discomfort, } \\
\text { colon cancer and polyps [78], } \\
\text { chemotherapy [79] }\end{array}$ & \\
\hline $\begin{array}{l}\text { Datura inoxia (Devil's } \\
\text { trumpet) }\end{array}$ & Solanaceae & China & $\begin{array}{l}\text { The withanolide, dinoxin B } \\
\text { exhibited significant toxic effect } \\
\text { against multiple human cancer cell } \\
\text { lines, most sensitive being breast } \\
\text { cancer cell lines [84] }\end{array}$ & \\
\hline $\begin{array}{l}\text { Dysoxylum } \\
\text { binectariferum (rose } \\
\text { mahogany) }\end{array}$ & Meliaceae & India & $\begin{array}{l}\text { Studied as treatment of tumors, } \\
\text { including leukemias, lymphomas, } \\
\text { and solid tumors }[8,85]\end{array}$ & \\
\hline $\begin{array}{l}\text { Echinacea (purple } \\
\text { coneflower) }\end{array}$ & Asteraceae & North America & $\begin{array}{l}\text { In treatment of brain tumors and } \\
\text { leukamias [86], cures side effects of } \\
\text { cancer [87] }\end{array}$ & \\
\hline $\begin{array}{l}\text { Emblica officinalis (amla, } \\
\text { Indian gooseberry) }\end{array}$ & Phyllanthaceae & India & $\begin{array}{l}\text { Inhibits growth and spread of } \\
\text { various cancers including that } \\
\text { of the breast, uterus, pancreas, } \\
\text { stomach, liver and ascites }[88,89] \text {, } \\
\text { antitumor [90] }\end{array}$ & $\begin{array}{l}\text { Antioxidant, antitussive, } \\
\text { immunomodulator, } \\
\text { cytoprotective, analgesic, } \\
\text { antimicrobial, antipyretic and } \\
\text { gastroprotective [91] }\end{array}$ \\
\hline $\begin{array}{l}\text { Ginkgo biloba (maidenhair } \\
\text { tree, Kew tree) }\end{array}$ & Ginkgoaceae & China & $\begin{array}{l}\text { Activity against carcinoma and } \\
\text { cancers of ovary, colon, prostate } \\
\text { and liver }[92,93]\end{array}$ & \\
\hline Gloriosa superba (glory lily) & Colchicaceae & Africa and Asia & Anticancer activity [94] & $\begin{array}{l}\text { Antileprotic,oxytocic, } \\
\text { stomachic, antimalarial, } \\
\text { purgative, anthelmintic, } \\
\text { cholagogue, alterative, } \\
\text { febrifuge [95] }\end{array}$ \\
\hline
\end{tabular}


Table 1: (Continued...)

\begin{tabular}{|c|c|c|c|c|}
\hline Plant name & Family & Native place & Anticancer activity & Other medicinal properties \\
\hline Glycine max (soybean) & Fabaceae & East Asia & $\begin{array}{l}\text { Inhibition of cancer cell } \\
\text { proliferation, causes cell } \\
\text { differentiation and initiation of } \\
\text { apoptosis [96], colon cancer [97] }\end{array}$ & \\
\hline $\begin{array}{l}\text { Glycyrrhiza glabra } \\
\text { Linn. (mulethi) }\end{array}$ & Fabaceae & $\begin{array}{l}\text { Southern Europe } \\
\text { and Asia }\end{array}$ & $\begin{array}{l}\text { Activity against cancers of breast, } \\
\text { lung, stomach, colon [98], liver, } \\
\text { kidney and leukemia }[99,100]\end{array}$ & $\begin{array}{l}\text { Antioxidant, antiviral } \\
\text { immunomodulatory, } \\
\text { anti-inflammatory, } \\
\text { cardioprotective [101] }\end{array}$ \\
\hline $\begin{array}{l}\text { Gossypium hirsutum (upland } \\
\text { cotton) }\end{array}$ & Malvaceae & $\begin{array}{l}\text { Mexico, West } \\
\text { Indies, and } \\
\text { America }\end{array}$ & $\begin{array}{l}\text { Inducing apoptosis and arresting } \\
\text { cancer cell division in G0/ } \\
\text { G1phase [102], breast cancer [103] }\end{array}$ & \\
\hline $\begin{array}{l}\text { Gynostemma } \\
\text { pentaphyllum (miracle grass, } \\
\text { fairy herb) }\end{array}$ & Cucurbitaceae & $\begin{array}{l}\text { China, Vietnam, } \\
\text { Korea and Japan }\end{array}$ & $\begin{array}{l}\text { Anticancer [104], anticancer } \\
\text { activity on prostate cancer [105] }\end{array}$ & $\begin{array}{l}\text { Antioxidant, or detoxifying } \\
\text { agent, anti-inflammatory } \\
\text { agent [106] }\end{array}$ \\
\hline $\begin{array}{l}\text { Hibiscus sabdariffa (rose } \\
\text { mallow) }\end{array}$ & Malvaceae & West Africa & $\begin{array}{l}\text { Inductive effect on human leukemia } \\
\text { cells [107] }\end{array}$ & \\
\hline $\begin{array}{l}\text { Hydrastis } \\
\text { canadensis (goldenseal) }\end{array}$ & Ranunculaceae & USA & $\begin{array}{l}\text { Berberine, isoquinoline alkaloid } \\
\text { extracted from Hydrastis canadensis } \\
\text { displays a number of beneficial } \\
\text { roles in the treatment of various } \\
\text { types of cancers [108] }\end{array}$ & Antimicrobial [109] \\
\hline $\begin{array}{l}\text { Kaempferia rotunda (bhumi } \\
\text { champa) }\end{array}$ & Zingiberaceae & China, India, Nepal & $\begin{array}{l}\text { Secondary metabolites as } \\
\text { cytotoxic [110] }\end{array}$ & Swellings and wounds [111] \\
\hline $\begin{array}{l}\text { Lagerstroemia } \\
\text { speciosa (giant } \\
\text { crape-myrtle) }\end{array}$ & Lythraceae & Southern Asia & Serves as anticancer [69] & Anti-diabetic [112] \\
\hline $\begin{array}{l}\text { Larrea } \\
\text { divaricata (chaparral) }\end{array}$ & Zygophyllaceae & America & $\begin{array}{l}\text { Acts as antimutagenic and } \\
\text { anticarcinogenic agent [113] }\end{array}$ & \\
\hline Linum usitatissimum (flax) & Linaceae & India & $\begin{array}{l}\text { Works against breast cancer, lung } \\
\text { cancer, prostate cancer and colon } \\
\text { cancer [114-116] }\end{array}$ & $\begin{array}{l}\text { Antidiabetic antiviral, } \\
\text { bactericidal, } \\
\text { anti-inflammatory and } \\
\text { antiatherosclerotic [117-119] }\end{array}$ \\
\hline $\begin{array}{l}\text { Lavandula } \\
\text { angustifolia (common } \\
\text { lavender) }\end{array}$ & Lamiaceae & $\begin{array}{l}\text { Western } \\
\text { Mediterranean }\end{array}$ & $\begin{array}{l}\text { Used to prevent multiplication of } \\
\text { cancer cells [120] }\end{array}$ & \\
\hline $\begin{array}{l}\text { Morinda citrifolia (Indian } \\
\text { mulberry) }\end{array}$ & Rubiaceae & $\begin{array}{l}\text { Asia and } \\
\text { Australasia }\end{array}$ & $\begin{array}{l}\text { Activity against lung cancer and } \\
\text { sarcomas [121] }\end{array}$ & \\
\hline $\begin{array}{l}\text { Momordica charantia (bitter } \\
\text { melon) }\end{array}$ & Cucurbitaceae & Asia and Africa & $\begin{array}{l}\text { Antitumor and antimutagenic } \\
\text { effects [122] }\end{array}$ & $\begin{array}{l}\text { Antimicrobial, antiviral, } \\
\text { anti-HIV [123,124] }\end{array}$ \\
\hline Nigella sativa (kalonji) & Ranunculaceae & $\begin{array}{l}\text { South and } \\
\text { Southwest Asia }\end{array}$ & $\begin{array}{l}\text { Activity against various cancers } \\
\text { such as cancers of the pancreas, } \\
\text { colon, uterus, prostate, malignant } \\
\text { ascites, malignant melanoma, } \\
\text { malignant lymphoma, sarcomas, } \\
\text { and leukemia [125-128] }\end{array}$ & \\
\hline $\begin{array}{l}\text { Ocimum sanctum (holy } \\
\text { basil) }\end{array}$ & Lamiaceae & $\begin{array}{l}\text { Indian } \\
\text { Subcontinent }\end{array}$ & $\begin{array}{l}\text { Inhibits growth and spread } \\
\text { of various cancers such as } \\
\text { breast cancer, liver cancer, and } \\
\text { sarcomas [129-131] }\end{array}$ & \\
\hline $\begin{array}{l}\text { Oldenlandia } \\
\text { diffusa (snake-needle grass) }\end{array}$ & Rubiaceae & China & $\begin{array}{l}\text { Inhibits growth and spread of } \\
\text { various cancers such as cancers } \\
\text { of rectum, lung, ovary, stomach, } \\
\text { uterus, colon, liver, brain, malignant } \\
\text { melanoma, lymphosarcoma, } \\
\text { malignant ascites, and } \\
\text { leukemia [132,133] }\end{array}$ & \\
\hline Olea europaea (olive tree) & Oleaceae & $\begin{array}{l}\text { Africa and } \\
\text { Southern Asia }\end{array}$ & $\begin{array}{l}\text { Prevents breast cancer and } \\
\text { colorectal cancer [34] }\end{array}$ & \\
\hline Oryza sativa (Asian rice) & Poaceae & Asia & Activity against Bowel cancer [134] & $\begin{array}{l}\text { Treatment of diabetes, } \\
\text { hypertension, cardiovascular } \\
\text { disease [135] }\end{array}$ \\
\hline $\begin{array}{l}\text { Oxycoccus acrocarpus (large } \\
\text { cranberry) }\end{array}$ & Ericaceae & United States & $\begin{array}{l}\text { Reduces the number of breast cancer } \\
\text { tumors, delay tumor development, } \\
\text { and slow metastasis of cancer to } \\
\text { lungs and lymph nodes [136-138] }\end{array}$ & \\
\hline
\end{tabular}


Table 1: (Continued...)

\begin{tabular}{|c|c|c|c|c|}
\hline Plant name & Family & Native place & Anticancer activity & Other medicinal properties \\
\hline Panax ginseng (ginseng) & Araliaceae & $\begin{array}{l}\text { North America and } \\
\text { Eastern Asia }\end{array}$ & $\begin{array}{l}\text { Inhibits growth and spread of } \\
\text { various cancers such as cancers of } \\
\text { breast, lung, ovary, colon, prostate, } \\
\text { renal cell carcinoma, malignant } \\
\text { lymphoma, malignant melanoma, } \\
\text { and leukemia }[139,140]\end{array}$ & \\
\hline $\begin{array}{l}\text { Plantago ovata (desert } \\
\text { Indian wheat) }\end{array}$ & Plantaginaceae & Asia & Anticancer activity [141] & $\begin{array}{l}\text { Treat hypercholesterolemia, } \\
\text { hyperglycemia [142] }\end{array}$ \\
\hline $\begin{array}{l}\text { Podophyllum } \\
\text { peltatum (mayapple) }\end{array}$ & Berberidaceae & USA & $\begin{array}{l}\text { Have been used to treat oral hairy } \\
\text { leukoplakia, combat skin cancers, } \\
\text { ovarian cancer, lung cancer } \\
\text { and prostate cancer, prostate } \\
\text { cancer }[143,144]\end{array}$ & \\
\hline $\begin{array}{l}\text { Polygonum } \\
\text { tinctorium (Chinese indigo) }\end{array}$ & Polygonaceae & Europe and Asia & $\begin{array}{l}\text { Studied in prevention of } \\
\text { leukemia [145] }\end{array}$ & \\
\hline $\begin{array}{l}\text { Raphanus sativus (cultivated } \\
\text { radish) }\end{array}$ & Brassicaceae & Southeast Asia & $\begin{array}{l}\text { Antitumor activity and anti-cancer } \\
\text { activity. 4-Methylsulfinyl-3-butenyl } \\
\text { isothiocyanate (MTBITC) found } \\
\text { in Raphanus sativus L., is a } \\
\text { well- known anticancer agent [149] }\end{array}$ & \\
\hline $\begin{array}{l}\text { Rhus succedanea (Japanese } \\
\text { wax tree) }\end{array}$ & Anacardiaceae & Asia & Anticancer activity [149] & Antimicrobial activities [150] \\
\hline $\begin{array}{l}\text { Rubia cordifolia (Indian } \\
\text { madder) }\end{array}$ & Rubiaceae & $\begin{array}{l}\text { Asia, Europe, and } \\
\text { Africa }\end{array}$ & $\begin{array}{l}\text { Growth and spread in cancers of } \\
\text { breast, colon, ovary, lung, cervix, } \\
\text { malignant ascites, malignant } \\
\text { melanoma sarcoma, malignant } \\
\text { lymphoma and leukemia }[151,152]\end{array}$ & \\
\hline $\begin{array}{l}\text { Ruscus aculeatus } \\
\text { (butcher's broom) }\end{array}$ & Liliaceae & Iran to USA & $\begin{array}{l}\text { Tumor-shrinking and } \\
\text { anti-estrogenic abilities [156] }\end{array}$ & \\
\hline $\begin{array}{l}\text { Sanguinaria } \\
\text { canadensis (bloodroot) }\end{array}$ & Papaveraceae & $\begin{array}{l}\text { Eastern North } \\
\text { America }\end{array}$ & $\begin{array}{l}\text { Studied in cervical cancer and } \\
\text { tumor treatments [157] }\end{array}$ & \\
\hline Saussurea lappa (costus) & Asteraceae & $\begin{array}{l}\text { Asia, Europe, and } \\
\text { North America }\end{array}$ & $\begin{array}{l}\text { Activity against cancers of the } \\
\text { colon, ovary, gastric central nervous } \\
\text { system, and lung }[158,159]\end{array}$ & \\
\hline $\begin{array}{l}\text { Scutellaria } \\
\text { barbata (skullcap) }\end{array}$ & Lamiaceae & Asia & $\begin{array}{l}\text { Works against many cancers such } \\
\text { as stomach, lung, prostate and } \\
\text { intestine }[160,161]\end{array}$ & \\
\hline $\begin{array}{l}\text { Silybum marianum (milk } \\
\text { thistle) }\end{array}$ & Asteraceae & $\begin{array}{l}\text { Mediterranean } \\
\text { country }\end{array}$ & $\begin{array}{l}\text { Inhibits growth of certain types of } \\
\text { cancer, including skin cancer, breast } \\
\text { cancer, ovarian cancer, and prostate } \\
\text { cancer [162-164] }\end{array}$ & \\
\hline $\begin{array}{l}\text { Solanum } \\
\text { nigrum (nightshade) }\end{array}$ & Solanaceae & $\begin{array}{l}\text { Americas, } \\
\text { Australasia and } \\
\text { Africa }\end{array}$ & $\begin{array}{l}\text { Inhibits growth and spread of } \\
\text { stomach cancer, malignant ascites, } \\
\text { cervical cancer, sarcomas, and } \\
\text { leukemia }[165,166]\end{array}$ & \\
\hline Spinacia oleracea (spinach) & Amaranthaceae & Ancient Persia & Prevents cancer [167] & \\
\hline $\begin{array}{l}\text { Sutherlandia } \\
\text { frutescens (cancer bush) }\end{array}$ & Fabaceae & Southern Africa & Anticancer activity [168] & $\begin{array}{l}\text { Antiviral, anti-inflammatory, } \\
\text { and antifungal [169] }\end{array}$ \\
\hline $\begin{array}{l}\text { Tabebuia species (trumpet } \\
\text { trees) }\end{array}$ & Bignoniaceae & $\begin{array}{l}\text { Central and South } \\
\text { America }\end{array}$ & $\begin{array}{l}\text { Having anti-cancerous } \\
\text { properties [170] }\end{array}$ & \\
\hline $\begin{array}{l}\text { Tabebuia } \\
\text { impetiginosa (roble) }\end{array}$ & Bignoniaceae & America & $\begin{array}{l}\text { Works against breast, leukemia and } \\
\text { prostate lines [8] }\end{array}$ & \\
\hline $\begin{array}{l}\text { Tanacetum } \\
\text { parthenium (feverfew) }\end{array}$ & Asteraceae & $\begin{array}{l}\text { Europe, North } \\
\text { America and } \\
\text { Australia }\end{array}$ & $\begin{array}{l}\text { Against cancer such as leukemia, } \\
\text { breast cancer, secondary lung } \\
\text { cancer, and secondary bone } \\
\text { cancer [171-173] }\end{array}$ & \\
\hline Taxus brevifolia (pacific yew) & Taxaceae & $\begin{array}{l}\text { Northwest of North } \\
\text { America }\end{array}$ & $\begin{array}{l}\text { Useful in breast and lung } \\
\text { cancer [174] }\end{array}$ & \\
\hline
\end{tabular}


Table 1: (Continued...)

\begin{tabular}{|c|c|c|c|c|}
\hline Plant name & Family & Native place & Anticancer activity & other medicinal properties \\
\hline $\begin{array}{l}\text { Terminalia belerica (kindal } \\
\text { tree) }\end{array}$ & Combretaceae & Southwest India & $\begin{array}{l}\text { Active fractions have shown } \\
\text { inhibition in proliferation of } \\
\text { breast (MCF-7), cervical (HeLa) and } \\
\text { brain (U87) cancer cells [175] }\end{array}$ & $\begin{array}{l}\text { Reported against diabetes, } \\
\text { ulcer, microbial problems and } \\
\text { hepatotoxicity }\end{array}$ \\
\hline $\begin{array}{l}\text { Trifolium pratense (red } \\
\text { clover) }\end{array}$ & Leguminaceae & $\begin{array}{l}\text { USA, Europe, } \\
\text { Australia and Asia }\end{array}$ & $\begin{array}{l}\text { Used in the cure of prostate and } \\
\text { endometrial cancer [176] }\end{array}$ & \\
\hline $\begin{array}{l}\text { Triticum aestivum (common } \\
\text { wheat) }\end{array}$ & Poaceae & Europe and USA & $\begin{array}{l}\text { Prevention of breast cancer and } \\
\text { colon cancer [177] }\end{array}$ & \\
\hline $\begin{array}{l}\text { Uncaria tormentosa (cat's } \\
\text { claw) }\end{array}$ & Rubiaceae & $\begin{array}{l}\text { South and Central } \\
\text { America }\end{array}$ & Have anticancer activity [178] & $\begin{array}{l}\text { Treatment of dengue, } \\
\text { gastritis, arthritis [179] }\end{array}$ \\
\hline $\begin{array}{l}\text { Vaccinium } \\
\text { angustifolium (lowbush } \\
\text { blueberry) }\end{array}$ & Ericaceae & $\begin{array}{l}\text { Easterncentral } \\
\text { Canada }\end{array}$ & Anticancer activities [180] & \\
\hline $\begin{array}{l}\text { Vaccinium myrtillus (blue } \\
\text { whortleberry) }\end{array}$ & Ericaceae & $\begin{array}{l}\text { Europe, USA, } \\
\text { Canada, Asia, } \\
\text { Greenland }\end{array}$ & & $\begin{array}{l}\text { Lowered risk for several } \\
\text { diseases, such as those } \\
\text { of heart, cancer, eye and } \\
\text { cardiovascular system }[38,181]\end{array}$ \\
\hline $\begin{array}{l}\text { Viscum album (European } \\
\text { mistletoe) }\end{array}$ & Santalaceae & Europe and Asia & $\begin{array}{l}\text { Bioactive ingredients modulated } \\
\text { extrinsic and intrinsic pathways in } \\
\text { cancer cells [182] }\end{array}$ & $\begin{array}{l}\text { Phenolic acids, } \\
\text { phenylpropanoids and } \\
\text { flavonoids with antioxidant } \\
\text { and anti-inflammatory } \\
\text { activities, which decrease } \\
\text { blood pressure }\end{array}$ \\
\hline Vitex negundo (chastetree) & Lamiaceae & Africa and Asia & $\begin{array}{l}\text { Antitumor and cytotoxic activity } \\
\text { against cancer cell [183] }\end{array}$ & \\
\hline Yucca glauca (soapweed) & Asparagaceae & North America & $\begin{array}{l}\text { Exhibits antitumor activity against } \\
\text { B16 melanoma [177] }\end{array}$ & \\
\hline Zingiber officinale (ginger) & Zingibaracae & North America & $\begin{array}{l}\text { Inhibits growth and spread of } \\
\text { various cancers including that of } \\
\text { the ovary [184], cervix, rectum, } \\
\text { liver, colon [185], urinary bladder, } \\
\text { neuroblastoma, oral cavity, skin } \\
\text { cancer, leukemia [186,187], and } \\
\text { breast cancer [188] }\end{array}$ & \\
\hline Ziziphus mauritiana (ber) & Rhamnaceae & $\begin{array}{l}\text { Indo-Malaysian } \\
\text { region of } \\
\text { South-East Asia }\end{array}$ & Inhibits growth of cancer cells [189] & \\
\hline
\end{tabular}

effective results of Aegle marmelos, Alpinia galangal, Catharanthus roseus, Dysoxylum binectariferum, Nigella sativa, etc., against lymphomas. Similarly, studies have been done where leukemias have been significantly controlled by plants such as A. galangal, Andrographis paniculata, Artemisia annua, Berberis vulgaris, and C. roseus. Anticancer activity was also found in plants such as Allium sativum, A. galangal, Amoora rohituka, A. paniculata, and Annona triloba when studied against breast cancer. A. sativum, A. galangal, A. paniculata, Azadirachta indica, B. vulgaris, and Brassica oleracea have shown significantly promising results against prostate cancer whereas A. paniculata, Asparagus racemosus, C. sinensis, Combretum caffrum, Ginkgo biloba against colon cancer.

Some plants such as Astragalus gummifera, Carmona retusa, Crocus sativus, Daphne genkwa, Datura metal, and Gloriosa superba seem to be all-rounder as they inhibit any cancerous or malignant growth. It is a well-known fact treatment of cancer either through chemotherapy or radiotherapy also carries some side effects, but studies on Codonopsis pilosula and C. longa have shown that they help the patient to overcome those side effects. In a recent qualitative system review by Evans and coworkers [190], cancer patients' experiences of using Viscum album (mistletoe) are reported, in which they have experienced demonstrable changes in their physical, emotional and psychological well-being as well as reduction in chemotherapy side effects after mistletoe treatment.

The shift toward natural healing is opening several doors to more patient-friendly treatment of cancer, and thus better options are generated to cure such a fatal disease. More research is required to isolate and purify active agents from these plants and thus bring out optimum potential of them.

\section{CONCLUSION}

There are many traditional systems of medicine around the globe, each with distinct style of treatment and cultural origins. Before the advent of modern medical treatments, people worldwide have utilized the natural resources to stay healthy and have claimed curing of various chronic and critical disorders [191-194]. This paper concentrated on highlighting the potential of vast plant resources as anticancer agents. Today, plant-derived active agents as well as chemically synthesized drugs are being studied, explored and undergoing clinical trial. Hence, the scientific study on the derivation of drugs through bioprospection and systematic conservation of the concerned medicinal plants are thus of great importance.

\section{REFERENCES}

1. World Cancer Report. International Agency for Research on Cancer; 2014. Available from: http://www.thehealthwell.info/node/725845.

2. Parkin DM, Bray F, Ferlay J, Pisani P. Global cancer statistics, 2002. CA Cancer J Clin 2005;55(2):74-108.

3. Corcé V, Gouin SG, Renaud S, Gaboriau F, Deniaud D. Recent advances in cancer treatment by iron chelators. Bioorg Med Chem Lett 2016;26(2):251-6

4. Soladoye MO, Amusa NA, Salmot O, Raji-Esan EC, Chukwuma TA. An ethnobotanical survey of anti-cancer plants in Ogun state, Nigeria. 
Ann Biol Res 2010;1(4):261-73.

5. Samuelsson G. Drugs of Natural Origin: A Textbook of Pharmacognosy. $4^{\text {th }}$ ed. Stockholm: Swedish Pharmaceutical Press; 1999.

6. Cragg GM, Newman DJ, Sander KM. Natural products in drug discovery and development. J Nat Prod 1997;60(1):52-60.

7. Kappor LD. CRC Handbook of Ayurvedic Medicinal Plants. $1^{\text {st }}$ ed. Florida: CRC Press Boca Raton; 1990.

8. Cragg GM, Newman DJ. Plants as source of anticancer agents. J Ethnopharmacol 2005;100(1-2):72-9.

9. Tulp M, Bohlin L. Functional versus chemical diversity: Is biodiversity important for drug discovery? Trends Pharmacol Sci 2002;23(5):225-31.

10. Tripathi P, Singh A. Identification of Cymbopogon species by using RAPD technique. World J Pharm Res 2014;3(6):2004-12.

11. Rao KV, Stanley AS, Nair H, Aalinkeel R, Chawda MS, Nair MP. Plant derived products as a source of cellular growth inhibitory pytochemicals on PC-3M, DU-145 and LNCaP prostate cancer cell lines. Curr Sci 2004;87:1585-8.

12. Rosangkima G, Prasad SB. Antitumour activity of some plants from Meghalaya and Mizoram against murine ascites Dalton's lymphoma. Indian J Exp Biol 2004;42(10):981-8.

13. Lambertini E, Piva R, Khan MT, Lampronti I, Bianchi N, Borgatti M, et al. Effect of extracts from Bangladeshi medicinal plants on in vitro proliferation of human breast cancer cell lines and expression of estrogen receptor alpha gene. Int J Oncol 2004;24:419.

14. Riyanto S, Sukari MA, Rahmani M. Alkaloids from Aegle marmelos (Rutacea). Malays J Anal Sci 2001;7(2):463-5.

15. Jagetia GC, Venkatesh P, Baliga MS. Aegle marmelos (L.) Correa inhibits the proliferation of transplanted Ehrlich ascites carcinoma in mice. Biol Pharm Bull 2005;28(1):58-64.

16. Hsing AW, Chokkalingam AP, Gao YT, Madigan MP, Deng J, Gridley G, et al. Allium vegetables and risk of prostate cancer: A population-based study. J Natl Cancer Inst 2002;94(21):1648-51.

17. Zhang Y, Moriguchi T, Saito H, Nishiyama N. Functional relationship between age-related immunodeficiency and learning deterioration. Eur J Neurosci 1998;10(12):3869-75.

18. González CA, Pera G, Agudo A, Bueno-de-Mesquita HB, Ceroti M, Boeing $\mathrm{H}$, et al. Fruit and vegetable intake and the risk of stomach and oesophagus adenocarcinoma in the European Prospective Investigation into Cancer and Nutrition (EPIC-EURGAST). Int $\mathrm{J}$ Cancer 2006;118(10):2559-66.

19. Setiawan VW, Yu GP, Lu QY, Lu ML, Yu SZ, Mu L, et al. Allium vegetables and stomach cancer risk in China. Asian Pac J Cancer Prev 2005;6(3):387-95

20. Boudreau MD, Beland FA. An evaluation of the biological and toxicological properties of Aloe barbadensis (Miller), Aloe vera. J Environ Sci Health C 2006;24:103-54.

21. Kim HS, Kacew S, Lee BM. In vitro chemopreventive effects of plant polysacchrides (Aloe barbadensis miller, Lentinus edodes, Ganoderma lucidum, and Coriolus vesicolor). Carcinogenesis 1999;20(8):1637-40.

22. Choi JH, Yoon SK, Lee KH, Seo MS, Kim DH, Hong SB, et al. Antitumor activity of cell suspension culture of green tea seed (Camellia sinensis L.). Biotechnol Bioprocess Eng 2006;11(5):396-401.

23. Suja S, Chinnaswamy P. Inhibition of in vitro cytotoxic effect evoked by Alpinia galanga and Alpinia officinarum on PC - 3 cell line. Anc Sci Life 2008;27(4):33-40.

24. Kaur A, Singh R, Dey CS, Sharma SS, Bhutani KK, Singh IP. Antileishmanial phenylpropanoids from Alpinia galanga (Linn.) Willd. Indian J Exp Biol 2010;48(3):314-7.

25. An N, Zou ZM, Tian Z, Luo XZ, Yang SL, Xu LZ. Diarylheptanoids from the rhizomes of Alpinia officinarum and their anticancer activity. Fitoterapia 2008;79(1):27-31

26. Chan LL, George S, Ahmad I, Gosangari SL, Abbasi A, Cunningham BT, et al. Cytotoxicity effects of Amoora rohituka and Chittagonga on breast and pancreatic cancer cells. Evid Based Complement Alternat Med 2011;2011:860605.

27. Luo DY. Inhibitory effect of refined Amorphophallus konjac on MNNG-induced lung cancers in mice. Zhonghua Zhong Liu Za Zhi 1992;14(1):48-50

28. Sheeja K, Shihab PK, Kuttan G. Antioxidant and anti-inflammatory activities of the plant Andrographis paniculata Nees. Immunopharmacol Immunotoxicol 2006;28(1):129-40.

29. Tripathi P, Singh A. Indigenous Asian plants against cancer: A comprehensive review. Int J Plant Res 2015;5(4):80-6.

30. Huidrom S, Deka M. Determination of antioxidant property of Andrographis paniculata. Indian J Drugs Dis 2012;1(1):12-7.

31. Kuyvenhoven JP, Meinders AE. Oxidative stress and diabetes mellitus pathogenesis of long - Term complications. Eur J Intern Med
1999;10:9-19.

32. Kebapci N, Belgin EF, Fahrettin A, Emine S, Canan D. Oxidative stress and antioxidant therapy in Type - II diabetes mellitus. Turk JEM 1999;4:153-62.

33. He K, Zhao GX, Shi G, Zeng L, Chao JF, McLaughlin JL. Additional bioactive annonaceous acetogenins from Asimina triloba (Annonaceae). Bioorg Med Chem 1997:5(3):501-6.

34. la Vecchia C, Negri E, Franceschi S, Decarli A, Giacosa A, Lipworth L. Olive oil, other dietary fats, and the risk of breast cancer (Italy). Cancer Causes Control 1995;6(6):545-50.

35. Yadav DN, Yogesh K, Aswani A. Antioxidant activity of peanut (Arachis hypogaea L.) skin extract: Application in soybean and mustard oil. Int J Food Process Technol 2014;1(1):26-31

36. Lala G, Malik M, Zhao C, He J, Kwon Y, Giusti MM, et al. Anthocyaninrich extracts inhibit multiple biomarkers of colon cancer in rats. Nutr Cancer 2006;54(1):84-93.

37. Valcheva-Kuzmanova SV, Belcheva A. Current knowledge of Aronia melanocarpa as a medicinal plant. Folia Med (Plovdiv) 2006;48(2):11-7.

38. Bell DR, Gochenaur K. Direct vasoactive and vasoprotective properties of anthocyanin-rich extracts. J Appl Physiol 2006;100(4):1164-70.

39. Cheng C, Ng DS, Chan TK, Gua SP, Ho WE, Koh AH, et al. Antiallergic action of anti-malarial drug artesunate in experimental mast cell-mediated anaphylactic models. Allergy 2013;68:195-203.

40. Wang J, Liu Y, Zhao J, Zhang W, Pang X. Saponins extracted from byproduct of Asparagus officinalis L. Suppress tumour cell migration and invasion through targeting Rho GTPase signalling pathway. J Sci Food Agric 2013;93(6):1492-8.

41. Mitra SK, Prakash NS, Sundaram R. Shatavarins (containing shatavarin IV) with anticancer activity from the roots of Asparagus racemosus. Indian J Pharmacol 2012;44(6):732-6.

42. Verma SP, Tripathi VC, Das P. Asparagus racemosus leaf extract inhibits growth of UOK 146 renal cell carcinoma cell line: Simultaneous oncogenic PRCCTFE3 fusion transcript inhibition and apoptosis independent cell death. Asian Pac J Cancer Prev 2014;15(5):1937-41.

43. Bopana N, Saxena S. Asparagus racemosus - Ethnopharmacological evaluation and conservation needs. J Ethnopharmacol 2007;110(1):1-15.

44. Sachan AK, Das DR, Dohare SS. Asparagus racemosus (Shatavari): An overview. Int J Pharm Chem Sci 2012;1(3):588-92.

45. Pistelli L, Bertoli A, Lepori E, Morelli I, Panizzi L. Antimicrobial and antifungal activity of crude extracts and isolated saponins from Astragalus verrucosus. Fitoterapia 2002;73:336-9.

46. Patel SM, Venkata KC, Bhattacharyya P, Sethi G, Bishayee A. Potential of neem (Azadirachta indica L.) for prevention and treatment of oncologic diseases. Semin Cancer Biol 2016;40-41:100-15.

47. Paul R, Prasad M, Sah NK. Anticancer biology of Azadirachta indica L (neem): A mini review. Cancer Biol Ther 2011;12(6):467-76.

48. Metwally FM, El-Mezayen HA, Moneim AE, Sharaf NE. Anti-tumor effect of Azadirachta indica (Neem) on murine solid Ehrlich carcinoma. Acad J Cancer Res 2014;7(1):38-45.

49. Elangovan V, Govindasamy S, Ramamoorthy N, Balasubramanian K. In vitro studies on the anticancer activity of Bacopa monniera. Fitoterapia 1995;66:211-5.

50. Ghosh T, Maity TK, Singh J. Evaluation of antitumor activity of stigmasterol, a constituent isolated from Bacopa monnieri Linn aerial parts against Ehrlich ascites carcinoma in mice. Orient Pharm Exp Med 2011;11(1):41-9.

51. Srivastava S, Mishra N, Misra U. Bacopa monniera - A future perspective. Int J Pharm Sci Drug Res 2009;1(3):154-7.

52. Gohil KJ, Patel JA. A review on Bacopa monniera: Current research and future prospects. Int J Green Pharm 2010;4(1):1-9.

53. Joy PP, Thomas J, Mathew S, Jose G, Joseph J. Medicinal plants. In: Bose TK, Kabir J, Das P, Joy PP, editors. Tropical Horticulture. $2^{\text {nd }}$ ed. Calcutta: Naya Prokash; 2001. p. 449-632.

54. Kuo C, Chi C, Liu T. The anti-inflammatory potential of berberine in-vitro and in-vivo. Cancer Lett 2004;203:127-37.

55. Takase H, Yamamoto K, Ito K, Yumioka E. Pharmacological studies on antidiarrheal effects of berberine and geranii herba. Nihon Yakurigaku Zasshi 1993;102(2):101-12.

56. Qadir S, Han J, Ji H, Chung H, Ahn J, Lee H. Effect of different extraction protocols on anticancer and antioxidant activities of Berberis koreana bark extracts. J Biosci Bioeng 2009;107:331-9.

57. Fukuda K, Hibiya Y, Mutoh M, Koshiji M, Akao S, Fujiwara H. Inhibition by berberine of cyclooxygenase-2 transcriptional activity in human colon cancer cells. J Ethnopharmacol 1999;66(2):227-33.

58. Küpeli E, Kosar M, Yesilada E, Hüsnü K, Baser C. A comparative study on the anti-inflammatory, antinociceptive and antipyretic effects of isoquinoline alkaloids from the roots of Turkish Berberis species. Life 
Sci 2002;72(6):645-57.

59. Yesilada E, Küpeli E. Berberis crataegina DC. Root exhibits potent anti-inflammatory, analgesic and febrifuge effects in mice and rats. J Ethnopharmacol 2002;79(2):237-48.

60. Talreja K, Moon A. Brassica oleracea: Phytochemical profiling in search for anticancer compounds. Int J Life Sci Pharm Sci 2014;4(4):1-10.

61. Grubbs CJ, Steele VE, Casebolt T, Juliana MM, Eto I, Whitaker LM, et al. Chemoprevention of chemically-induced mammary carcinogenesis by indole-3-carbinol. Anticancer Res 1995;15(3):709-16.

62. Lee $\mathrm{CH}$, Wang JD, Chen PC. Risk of liver injury associated with Chinese herbal products containing radix bupleuri in 639,779 patients with hepatitis B virus infection. PLoS One 2011;6(1):e16064.

63. Davalli P, Rizzi F, Caporali A, Pellacani D, Davoli S, Bettuzzi S, et al. Anticancer activity of green tea polyphenols in prostate gland. Oxid Med Cell Longev 2012;2012:984219.

64. Bhatt PR, Pandya KB, Sheth NR. Camellia sinensis (L): The medicinal beverage: A review. Int J Pharm Sci Rev Res 2010;3(2):3-6.

65. Katiyar SK, Ahmad N, Mukhtar H. Green tea and skin. Arch Dermatol 2000;136(8):989-94

66. Li S, Zhang Z, Cain A, Wang B, Long M, Taylor J. Antifungal activity of camptothecin, trifolin, and hyperoside isolated from Camptotheca acuminata. J Agric Food Chem 2005;53(1):32-7.

67. Chandrappa CP, Govindappa M, Kumar NV, Channabasava R, Sadananda TS, Sharanappa P. In vitro anticancer activity of quercetin isolated from Carmona retusa (Vahl.) masam on human hepatoma cell line (hepg2). IOSR J Pharm Biol Sci 2014;9(6):85-91

68. Duflos A, Kruczynski A, Barret JM. Novel aspects of natural and modified Vinca alkaloids. Curr Med Chem Anticancer Agents 2002;2(1):55-70

69. Gajalakshmi S, Vijayalakshmi S, Devi RV. Pharmacological activities of Catharanthus roseus: A perspective review. Int J Pharm Bio Sci 2013;4(2):431-9.

70. Sain M, Sharma V. Catharanthus roseus (An anti-cancerous drug yielding plant) - A review of potential therapeutic properties. Int J Pure Appl Biosci 2013;1(6):139-42.

71. Patil PJ, Ghosh JS. Antimicrobial activity of Catharanthus roseus - A detailed study. Br J Pharmacol Toxicol 2010;1(1):40-4.

72. Wu M, Lu P, Shi L, Li S. Traditional Chinese patent medicines for cancer treatment in China: A nationwide medical insurance data analysis. Oncotarget 2015;6(35):38283-95

73. Xu C, Liu Y, Yuan G, Guan M. The contribution of side chains to antitumor activity of a polysaccharide from Codonopsis pilosula. Int $\mathrm{J}$ Biol Macromol 2012;50(4):891-4.

74. Yang C, Gou Y, Chen J, An J, Chen W, Hu F. Structural characterization and antitumor activity of a pectic polysaccharide from Codonopsis pilosula. Carbohydr Polym 2013;98(1):886-95.

75. Sapio L, Gallo M, Illiano M, Chiosi E, Naviglio D, Spina A, et al. The natural cAMP elevating compound forskolin in cancer therapy: Is it time? J Cell Physiol 2017;232(5):922-7.

76. Pettit GR, Singh SB, Boyd MR, Hamel E, Pettit RK, Schmidt JM, et al. Antineoplastic agents 291. Isolation and synthesis of combretastatins A-4, A-5, and A-6(1a) J Med Chem 1995;38(10):1666-72.

77. Abdullallaev JF, Caballero OH, Riveron NL, Pereda MR, Rivera LR, Manuel HJ, et al. Espinosa A. J J Rev Invest Clin 2002;54:430-4.

78. Akram M, Shahab U, Ahmed A, Khan U, Hannan A, Mohiuddin E, et al. Curcuma longa and curcumin: A review article. Rom J Biol Plant Biol 2010;55(2):65-70.

79. Samini F, Samarghandian S, Borji A, Mohammadi G, Bakaian M. Curcumin pretreatment attenuates brain lesion size and improves neurological function following traumatic brain injury in the rat. Pharmacol Biochem Behav 2013;110:238-44

80. Du WJ, Yang XL, Song ZJ, Wang JY, Zhang WJ, He X, et al. Antitumor activity of total flavonoids from Daphne genkwa in colorectal cancer. Phytother Res 2016;30(2):323-30.

81. Reddy VJ, Rao GD, Lakshmi GR. A review on anti-arthritic activity of some medicinal plants. J Glob Trends Pharm Sci 2014;5(4):2061-73.

82. Alam MN, Bristi NJ, Rafiquzzaman M. Review on in vivo and in vitro methods evaluation of antioxidant activity. Saudi Pharm J 2013;21(2):143-52.

83. Uyangaa E, Choi JY, Ryu HW, Oh SR, Eo SK. Anti-herpes activity of vinegar-processed Daphne genkwa flos via enhancement of natural killer cell activity. Immune Netw 2015;15(2):91-9.

84. Vermillion K, Holguin FO, Berhow MA, Richins RD, Redhouse T, O'Connell MA, et al. Dinoxin B, a withanolide from Datura inoxia leaves with specific cytotoxic activities. J Nat Prod 2011;74(2):267-71.

85. Arguello F, Alexander M, Sterry JA, Tudor G, Smith EM, Kalavar NT, et al. Flavopiridol induces apoptosis of normal lymphoid cells, causes immunosuppression, and has potent antitumor activity in vivo against human leukemia and lymphoma xenografts. Blood 1998;91(7):2482-90.

86. Miller SC. Echinacea: A miracle herb against aging and cancer? Evidence in vivo in mice. Evid Based Complement Alternat Med 2005;2(3):309-14

87. Huntley AL, Thompson Coon J, Ernst E. The safety of herbal medicinal products derived from Echinacea species: A systematic review. Drug Saf 2005;28(5):387-400.

88. Ngamkitidechakul C, Jaijoy K, Hansakul P, Soonthornchareonnon N, Sireeratawong S. Antitumour effects of Phyllanthus emblica L.: Induction of cancer cell apoptosis and inhibition of in vivo tumour promotion and in vitro invasion of human cancer cells. Phytother Res 2010;24(9):1405-13.

89. Zhang YJ, Nagao T, Tanaka T, Yang CR, Okabe H, Kouno I. Antiproliferative activity of the main constituents from Phyllanthus emblica. Biol Pharm Bull 2004;27(2):251-5.

90. Jose JK, Kuttan G, Kuttan R. Antitumour activity of Emblica officinalis. J Ethnopharmacol 2001;75(2-3):65-9.

91. Madhuri S, Pandey G, Verma KS. Antioxidant, immunomodulatory and anticancer activities of Emblica officinalis: An overview. Int Res J Pharm 2011;2(8):38-42.

92. Suzuki R, Kohno H, Sugie S, Sasaki K, Yoshimura T, Wada K, et al. Preventive effects of extract of leaves of ginkgo (Ginkgo biloba) and its component bilobalide on azoxymethane-induced colonic aberrant crypt foci in rats. Cancer Lett 2004;210(2):159-69.

93. Sakarkar DM, Deshmukh VN. Ethnopharmacological review of traditional medicinal plants for anticancer activity. Int J PharmTech Res 2011;3(1):298-308

94. Clewer HW, Green SJ, Tutin F. Constituents of Gloriosa superba. J Chem Soc 1915;107:835-46.

95. Pawar BM, Wavhal VP, Pawar ND, Agarwal MR, Shinde PB, Kamble HV. Anthelmintic activity of Gloriosa superba Linn (Liliaceae). Int J PharmTech Res 2010;2(2):1483-7.

96. Petrakis NL, Barnes S, King EB, Lowenstein J, Wiencke J, Lee MM, et al. Stimulatory influence of soy protein isolate on breast secretion in pre - And postmenopausal women. Cancer Epidemiol Biomarkers Prev 1996;5(10):785-94.

97. Kim JM, Kim JS, Yoo H, Choung MG, Sung MK. Effects of black soybean [Glycine $\max (\mathrm{L}$.) Merr.] seed coats and its anthocyanidins on colonic inflammation and cell proliferation in vitro and in vivo. J Agric Food Chem 2008;56(18):8427-33.

98. Lee CK, Park KK, Lim SS, Park JH, Chung WY. Effects of the licorice extract against tumor growth and cisplatin-induced toxicity in a mouse xenograft model of colon cancer. Biol Pharm Bull 2007;30(11):2191-5.

99. Shibata S. A drug over the millennia: Pharmacognosy, chemistry, and pharmacology of licorice. Yakugaku Zasshi 2000;120(10):849-62.

100. Kobayashi M, Fujita K, Katakura T, Utsunomiya T, Pollard RB, Suzuki F. Inhibitory effect of glycyrrhizin on experimental pulmonary metastasis in mice inoculated with B16 melanoma. Anticancer Res 2002;22(6C):4053-8

101. Badr SE, Sakr DM, Mahfouz SA, Abdelfattah MS. Licorice (Glycyrrhiza glabra L.): Chemical composition and biological impacts. Res J Pharm Biol Chem Sci 2013;4(3):606-21.

102. Nagatsu A, Zhang H, Mizukami H, Okuyama H, Sakakibara J, Tokuda $\mathrm{H}$, et al. Tyrosinase inhibitory and anti-tumor promoting activities of compounds isolated from Safflower (Carthamus Tinctorius L.) and Cotton (Gossypium Hirsutum L.) oil cakes. Nat Prod Lett 2000;14(3). DOI: 10.1080/10575630008041225.

103. Hartwell JL. Plants used against cancer: A survey. Lloydia 1971;30(4):386-425.

104. Xing SF, Jang M, Wang YR, Piao XL. A new dammarane-type saponin from Gynostemma pentaphyllum induces apoptosis in A549 human lung carcinoma cells. Bioorg Med Chem Lett 2016;26(7):1754-9.

105. Zhang XS, Zhao C, Tang WZ, Wu XJ, Zhao YQ. Gypensapogenin H, a novel dammarane-type triterpene induces cell cycle arrest and apoptosis on prostate cancer cells. Steroids 2015;104:276-83.

106. Lin CC, Huang PC, Lin JM. Antioxidant and hepatoprotective effects of Anoectochilus formosanus and Gynostemma pentaphyllum. Am J Chin Med 2000;28(1):87-96.

107. Tseng TH, Hsu JD, Lo MH, Chu CY, Chou FP, Huang CL, et al. Inhibitory effect of Hibiscus protocatechuic acid on tumor promotion in mouse skin. Cancer Lett 1998;126(2):199-207.

108. Zhao Y, Jing Z, Li Y, Mao W. Berberine in combination with cisplatin suppresses breast cancer cell growth through induction of DNA breaks and caspase-3-dependent apoptosis. Oncol Rep 2016;36(1):567-72.

109. Scazzocchio F, Cometa MF, Tomassini L, Palmery M. Antibacterial activity of Hydrastis canadensis extract and its major isolated alkaloids. 
Planta Med 2001;67(1):561-4

110.Lallo S, Lee S, Dibwe DF, Tezuka Y, Morita H. A new polyoxygenated cyclohexane and other constituents from Kaempferia rotunda and their cytotoxic activity. Nat Prod Res 2014;28(20):1754-9.

111.Imam SA, Rout SK, Sutar N, Sharma US, Sutar R. Wound healing activity of Kaempferia rotunda Linn leaf extract. Int J Curr Microbiol App Sci 2013;2(12):74-8.

112. Saha BK, Bhuiyan NH, Mazumder K, Haque KM. Hypoglycemic activity of Lagerstroemia speciosa L. Extract on streptozotocin-induced diabetic rat: Underlying mechanism of action. Bangladesh J Pharmacol 2009;4:79-83.

113. McDonald RW, Bunjobpon W, Liu T, Fessler S, Pardo OE, Freer IK, et al. Synthesis and anticancer activity of nordihydroguaiaretic acid (NDGA) and analogues. Anticancer Drug Des 2001;16(6):261-70.

114.Chen J, Wang L, Thompson LU. Flaxseed and its components reduce metastasis after surgical excision of solid human breast tumor in nude mice. Cancer Lett 2006;234(2):168-75.

115.Zanwar AA, Hegde MV, Bodhankar SL. In vitro antioxidant activity of ethanolic extract of Linum usitatissimum. Pharmacol Online 2010;1:683-96.

116. Rajesha KN, Murthy C, Kumar KM, Madhusudhan B, Ravishankar GA. Antioxidant potentials of flax seed by in vivo model. J Agric Food Chem 2006;54:3794-9.

117.Prasad K. Oxidative stress as a mechanism of diabetes in diabetic BB prone rats: Effect of secoisolariciresinol diglucoside (SDG). Mol Cell Biochem 2000;209(1-2):89-96.

118.Collins TF, Sprando RL, Black TN, Olejnik N, Wiesenfeld PW, Babu US, et al. Effects of flaxseed and defatted flaxseed meal on reproduction and development in rats. Food Chem Toxicol 2003;41(6):819-34 .

119. Kinniry P, Amrani Y, Vachani A, Solomides CC, Arguiri E, Workman A, et al. Dietary flaxseed supplementation ameliorates inflammation and oxidative tissue damage in experimental models of acute lung injury in mice. J Nutr 2006;136(6):1545-51.

120. Nelson NJ. Scents or nonsense: Aromatherapy's benefits still subject to debate. J Natl Cancer Inst 1997;89(18):1334-6.

121. Wang MY, West BJ, Jensen CJ, Nowicki D, Su C, Palu AK, et al. Morinda citrifolia (Noni): A literature review and recent advances in Noni research. Acta Pharmacol Sin 2002;23(12):1127-41.

122. Omoregbe RE, Ikuebe OM, Ihimire IG. Antimicrobial activity of some medicinal plants extracts on Escherichia coli, Salmonella paratyphi and Shigella dysenteriae. Afr J Med Med Sci 1996;25(4):373-5.

123. Kumar DS, Sharathnath KV, Yogeswaran P, Harani A, Sudhakar K, Sudha $\mathrm{P}$, et al. A medicinal potency of Momordica charantia. Int J Pharm Sci Rev Res 2010;1(2):95-100.

124. Leelaprakash G, Rose JC, Gowtham BM, Javvaji PK, Prasad S. In vitro antimicrobial and antioxidant activity of Momordica charantia Leaves. Pharmacophore 2011;2(4):244-52.

125. Badary OA, Al-Shabanah OA, Nagi MN, Al-Rikabi AC, Elmazar MM. Inhibition of benzo(a)pyrene-induced forestomach carcinogenesis in mice by thymoquinone. Eur J Cancer Prev 1999;8(5):435-40.

126. Agbaria R, Gabarin A, Dahan A, Ben-Shabat S. Anticancer activity of Nigella sativa (black seed) and its relationship with the thermal processing and quinone composition of the seed. Drug Des Devel Ther 2015;9:3119-24.

127. Salomi NJ, Nair SC, Jayawardhanan KK, Varghese CD, Panikkar KR. Antitumour principles from Nigella sativa seeds. Cancer Lett 1992;63(1):41-6.

128. Gali-Muhtasib H, Diab-Assaf M, Boltze C, Al-Hmaira J, Hartig R, Roessner $\mathrm{A}$, et al. Thymoquinone extracted from black seed triggers apoptotic cell death in human colorectal cancer cells via a p53dependent mechanism. Int J Oncol 2004;25(4):857-66.

129. Sharma P, Prakash O, Shukla A, Rajpurohit CS, Vasudev PG, Luqman S, et al. Structure-activity relationship studies on holy basil (Ocimum sanctum L.) based flavonoid orientin and its analogue for cytotoxic activity in liver cancer cell line hepG2. Comb Chem High Throughput Screen 2016;19(8):656-66.

130. Manaharan T, Thirugnanasampandan R, Jayakumar R, Kanthimathi MS, Ramya G, Ramnath MG. Purified essential oil from Ocimum sanctum Linn. Triggers the apoptotic mechanism in human breast cancer cells. Pharmacogn Mag 2016;12 Suppl 3:S327-31.

131. Singh N, Verma P, Pandey BR, Bhalla M. Therapeutic potential of Ocimum sanctum in prevention and treatment of cancer and exposure to radiation: An overview. Int J Pharm Sci Drug Res 2012;4(2):97-104.

132. Gupta S, Zhang D, Yi J, Shao J. Anticancer activities of Oldenlandia diffusa. J Herb Pharmacother 2004;4(1):21-33.

133. Madhuri S, Pandey G. Some anticancer medicinal plants of foreign origin. Curr Sci 2009;96(6):779-83.
134. Weisburger JH, Reddy BS, Rose DP, Cohen LA, Kendall ME, Wynder EL. Protective mechanisms of dietary fibers in nutritional carcinogenesis. Basic Life Sci 1993;61:45-63.

135. Umadevi MR, Pushpa R, Sampathkumar KP, Bhowmik D. Ricetraditional medicinal plant in India. J Pharmacogn Phytochem 2012;1(1):6-12.

136. Harkins KJ. What's the use of cranberry juice? Age Ageing 2000;29(1):9-12

137. Neto CC. Cranberry and blueberry: Evidence for protective effects against cancer and vascular diseases. Mol Nutr Food Res 2007;51(6):652-64.

138. MacLean MA, Scott BE, Deziel BA, Nunnelley MC, Liberty AM, Gottschall-Pass KT, et al. North American cranberry (Vaccinium macrocarpon) stimulates apoptotic pathways in DU145 human prostate cancer cells in vitro. Nutr Cancer 2011;63(1):109-20.

139. Lee YJ, Jin YR, Lim WC, Park WK, Cho JY, Jang S, et al. Ginsenoside$\mathrm{Rb} 1 \mathrm{acts}$ as a weak phytoestrogen in MCF-7 human breast cancer cells. Arch Pharm Res 2003;26(1):58-63.

140. Shibata S. Chemistry and cancer preventing activities of ginseng saponins and some related triterpenoid compounds. J Korean Med Sci 2001;16 Suppl: S28-37.

141. Gerber M. Fiber and breast cancer: Another piece of the puzzle - But still an incomplete picture. J Natl Cancer Inst 1996;88(13):857-8.

142. Haddadian K, Haddadian K, Zahmatkash M. A review of Plantgo plant. Indian J Tradit Knowl 2014;13(4):681-5.

143. O'Connor SE. Plant biochemistry. Fighting cancer while saving the mayapple. Science 2015;349(6253):1167-8

144. Hu S, Zhou Q, Wu WR, Duan YX, Gao ZY, Li YW, et al. Anticancer effect of deoxypodophyllotoxin induces apoptosis of human prostate cancer cells. Oncol Lett 2016;12(4):2918-23.

145. Koya-Miyata S, Kimoto T, Micallef MJ, Hino K, Taniguchi M, Ushio S, et al. Prevention of azoxymethane-induced intestinal tumors by a crude ethyl acetate-extract and tryptanthrin extracted from Polygonum tinctorium Lour. Anticancer Res 2001;21(5):3295-300.

146. Collins NH, Lessey EC, DuSell CD, McDonnell DP, Fowler L. Characterization of antiestrogenic activity of the Chinese herb, Prunella vulgaris, using in vitro and in vivo (mouse xenograft) models. Biol Reprod 2009;80:375-83.

147. Umadevi M, Kumar KP, Bhowmik D, Duraivel S. Traditionally used anticancer herbs in India. J Med Plants Stud 2013;1(3):56-74.

148. Hwang YJ, Lee EJ, Kim HR, Hwang KA. In vitro antioxidant and anticancer effects of solvent fractions from Prunella vulgaris var. Lilacina. BMC Complement Altern Med 2013;13:310.

149. Wang N, Wang W, Huo P, Liu CQ, Jin JC, Shen LQ. Mitochondriamediated apoptosis in human lung cancer A549 cells by 4-methylsulfinyl-3-butenyl isothiocyanate from radish seeds. Asian Pac J Cancer Prev 2014;15(5):2133-9.

150. Shrestha S, Subaramaihha SR, Subbaiah SG, Eshwarappa RS, Lakkappa DB. Evaluating the antimicrobial activity of methonolic extract of Rhus succedanea leaf gall. Bioimpacts 2013;3:195-8.

151. Adwankar MK, Chitnis MP. In vivo anti-cancer activity of RC-18: A plant isolate from Rubia cordifolia, Linn. Against a spectrum of experimental tumour models. Chemotherapy 1982;28(4):291-3.

152. Patel PR, Nagar AA, Patel RC, Rathod DK, Patel VR. In vitro anticancer activity of Rubia cordifolia against Hela and HEP 2 cell lines. Int J Pharm Pharm Sci 2011;3(2):70-1

153. Vasas A, Orbán-Gyapai O, Hohmann J. The genus rumex: Review of traditional uses, phytochemistry and pharmacology. J Ethnopharmacol $2015 ; 175: 198-228$

154. Kucekova Z, Mlcek J, Humpolicek P, Rop O, Valasek P, Saha P. Phenolic compounds from Allium schoenoprasum, Tragopogon pratensis and Rumex acetosa and their antiproliferative effects. Molecules 2011;16(11):9207-17.

155. He SY, Gao YJ, Shentu JL, Chen KB. Combined effects of copper and simulated acid rain on copper accumulation, growth, and antioxidant enzyme activities of Rumex acetosa. Ying Yong Sheng Tai Xue Bao 2011;22:481-7.

156. Cluzan RV, Alliot F, Ghabboun S, Pascot M. Treatment of secondary lymphedema of the upper limb with CYCLO 3 FORT. Lymphology 1996;29(1):29-35

157. Chang MC, Chan CP, Wang YJ, Lee PH, Chen LI, Tsai YL, et al. Induction of necrosis and apoptosis to $\mathrm{KB}$ cancer cells by sanguinarine is associated with reactive oxygen species production and mitochondrial membrane depolarization. Toxicol Appl Pharmacol 2007;218(2):143-51.

158. Jia JM, Wu CF, Liu W, Yu H, Hao Y, Zheng JH, et al. Antiinflammatory and analgesic activities of the tissue culture of Saussurea involucrata. 
Biol Pharm Bull 2005;28(9):1612-4

159. Ko SG, Kim HP, Jin DH, Bae HS, Kim SH, Park CH, et al. Saussurea lappa induces G2-growth arrest and apoptosis in AGS gastric cancer cells. Cancer Lett 2005;220(1):11-9.

160. Yin X, Zhou J, Jie C, Xing D, Zhang Y. Anticancer activity and mechanism of Scutellaria barbata extract on human lung cancer cell line A549. Life Sci 2004;75(18):2233-44

161. Yu J, Liu H, Lei J, Tan W, Hu X, Zou G. Antitumor activity of chloroform fraction of Scutellaria barbata and its active constituents. Phytother Res 2007;21(9):817-22.

162. Zi X, Grasso AW, Kung HJ, Agarwal R. A flavonoid antioxidant, silymarin, inhibits activation of erbB1 signaling and induces cyclindependent kinase inhibitors, G1 arrest, and anti-carcinogenic effects in human prostate carcinoma DU145 cells. Cancer Res 1999;59:622-32.

163. Kalla PK, Chitti S, Aghamirzaei ST, Senthilkumar R, Arjunan S. Anticancer activity of silymarin on MCF-7 and NCIH-23 cell lines. Adv Biol Res 2014;8(2):57-61.

164. Ahmad N, Gali H, Javed S, Agarwal R. Skin cancer chemopreventive effects of a flavonoid antioxidant silymarin are mediated via impairment of receptor tyrosine kinase signaling and perturbation in cell cycle progression. Biochem Biophys Res Commun 1998;247(2):294-301.

165. Jian L, Qingwang L, Tao F, Kun L. Aqueous extract of Solanum nigrum inhibit growth of cervical carcinoma (U14) via modulating immune response of tumor bearing mice and inducing apoptosis of tumor cells. Fitoterapia 2008;79(7-8):548-56.

166. Li J, Li QW, Gao DW, Han ZS, Lu WZ. Antitumor and immunomodulating effects of polysaccharides isolated from Solanum nigrum Linne. Phytother Res 2009;23(11):1524-30.

167. Ahn YO Diet and stomach cancer in Korea. Int $\mathrm{J}$ Cancer 1997; Suppl 10:7-9.

168. Chinkwo KA. Sutherlandia frutescens extracts can induce apoptosis in cultured carcinoma cells. J Ethnopharmacol 2005;98(1-2):163-70.

169. Ojewole JA. Analgesic, antiinflammatory and hypoglycemic effects of Sutherlandia frutescens R. BR. (variety Incana E. MEY.) [Fabaceae] shoot aqueous extract. Methods Find Exp Clin Pharmacol 2004;26(6):409-16.

170. Cassileth BR. Evaluating complementary and alternative therapies for cancer patients. CA Cancer J Clin 1999;49(6):362-75.

171. Won YK, Ong CN, Shi X, Shen HM. Chemopreventive activity of parthenolide against UVB-induced skin cancer and its mechanisms. Carcinogenesis 2004;25(8):1449-58

172. Pareek A, Suthar M, Rathore GS, Bansal V. Feverfew (Tanacetum parthenium L.): A systematic review. Pharmacogn Rev 2011;5(9):103-10

173. Kumar V, Tyagi D. Chemical composition and biological activities of essential oils of genus Tanacetum - A review. J Pharmacogn Phytochem 2013;2(3):159-63

174. Ram VJ, Kumari S. Natural products of plant origin as anticancer agents. Drug News Perspect 2001;14(8):465-82.

175. Basu T, Panja S, Ghate NB, Chaudhuri D, Mandal N. Antioxidant and antiproliferative effects of different solvent fractions from Terminalia belerica Roxb. Fruit on various cancer cells. Cytotechnol 2016. DOI: 10.1007/s10616-016-0051-6.

176. Jarred RA, Keikha M, Dowling C. Induction of apoptosis in low to moderate-grade human prostate carcinoma by red clover-derived dietary isoflavones. Cancer Epidemiol Biomarkers Prev 2002;11:1689-96.
177. Ortiz-Martinez M, Winkler R, García-Lara S. Preventive and therapeutic potential of peptides from cereals against cancer. J Proteomics 2014;111:165-83.

178. Riva L, Coradini D, Di Fronzo G, De Feo V, De Tommasi N, De Simone F, et al. The antiproliferative effects of Uncaria tomentosa extracts and fractions on the growth of breast cancer cell line. Anticancer Res 2001;21(4A):2457-61.

179. Reis SR, Valente LM, Sampaio AL, Siani AC, Gandini M, Azeredo EL, et al. Immunomodulating and antiviral activities of Uncaria tomentosa on human monocytes infected with dengue virus-2. Int Immunopharmacol 2008;8(3):468-76.

180. Bomser J, Madhavi DL, Singletary K, Smith MA. In vitro anticancer activity of fruit extracts from Vaccinium species. Planta Med 1996;62(3):212-6

181. Seeram NP. Berry fruits for cancer prevention: Current status and future prospects. J Agric Food Chem 2008;56(3):630-5.

182. Attar R, Tabassum S, Fayyaz S, Ahmad MS, Nogueira DR, Yaylim I, et al. Natural products are the future of anticancer therapy: Preclinical and clinical advancements of Viscum album phytometabolites. Cell Mol Biol (Noisy-le-grand) 2015;61(6):62-8.

183. Díaz F, Chávez D, Lee D, Mi Q, Chai HB, Tan GT, et al. Cytotoxic flavone analogues of vitexicarpin, a constituent of the leaves of Vitex negundo. J Nat Prod 2003;66(6):865-7.

184. Ramakrishnan R. Anticancer properties of Zingiber officinale - Ginger: A review. Int J Med Pharm Sci 2013;3(5):11-20.

185. Abdullah S, Abidin SA, Murad NA, Suzana M, Ngah WZ, Yusof YA. Ginger extract (Zingiber officinale) triggers apoptosis and G0/G1 cells arrest in HCT 116 and HT 29 colon cancer cell lines. Afr J Biochem Res 2010;4(4):134

186. Habib SH, Makpol S, Abdul Hamid NA, Das S, Ngah WZ, Yusof YA. Ginger extract (Zingiber officinale) has anti-cancer and antiinflammatory effects on ethionine-induced hepatoma rats. Clinics (Sao Paulo) 2008;63(6):807-13

187. Kumar KM, Asish GR, Sabu M, Balachandran I. Significance of gingers (Zingiberaceae) in Indian system of medicine - Ayurveda: An overview. Anc Sci Life 2013;32(4):253-61.

188. Rahman S, Salehin F, Iqbal A. In vitro antioxidant and anticancer activity of young Zingiber officinale against human breast carcinoma cell lines. BMC Complement Altern Med 2011;11:76-84.

189. Bhatia A, Mishra T. Hypoglycemic activity of Ziziphus mauritiana aqueous ethanol seed extract in alloxan-induced diabetic mice. Pharm Biol 2010;48(6):604-10

190. Evans M, Bryant S, Huntley AL, Feder G. Cancer patients' experiences of using mistletoe (Viscum album): A qualitative systematic review and synthesis. J Altern Complement Med 2016;22(2):134-44.

191. Tripathy G, Pradhan D, Shaktiprasad PS, Dasmohapatra T. Evaluation of plant extracts against lung cancer using h460 cell line. Asian J Pharm Clin Res 2016;9(2):227-9.

192. Nazeema BB, Julie J, Abirami J, Kumareasan R, Muthukumaran T, Rajasree S, et al. Anti-cancer activity of Datura metel on mcf-7 cell line. Asian J Pharm Clin Res 2014;7(1):181-3.

193. Elgadir MA, Salama M, Adam A. Anti-breast cancer from various natural sources, review. Int J Pharm Pharm Sci 2015;7(2):44-7.

194. Thirugnanasambantham P, Senthil K. In vitro and omics technologies opens a new avenue for deciphering withanolide metabolism in Withania somnifera. Int J Pharm Pharm Sci 2016;8(7):17-26. 